\title{
Coexistência de Hipotiroidismo e Polimiosite ${ }^{(*)}$
}

\section{Coexistence of Hypothyroidism and Polymyositis}

\author{
Maize Fernanda Bonim Singh ${ }^{(1)}$, Sandra Regina M. Fernandes ${ }^{(2)}$, Lilian Tereza Lavras Costallat ${ }^{(3)}$, \\ Manoel Barros Bértolo ${ }^{(2)}$, Luciano de Souza Queiroz ${ }^{(4)}$ e Adil Muhib Samara ${ }^{(3)}$
}

\section{RESUMO}

Pacientes com hipotiroidismo freqüentemente apresentam sintomas músculo-esqueléticos e aumento de enzimas musculares, como a creatinaquinase (CK). Com o tratamento hormonal adequado é incomum ocorrer grandes aumentos de CK e manutenção de queixas musculares. Este trabalho relata o caso de uma paciente com hipotiroidismo, queixa de fraqueza muscular proximal e aumento de CK, sem melhora clínica com uso de levotiroxina. O diagnóstico de polimiosite foi confirmado por eletroneuromiografia e biópsia muscular. Após tratamento com prednisona e metotrexato, além de adequação da dose de levotiroxina, houve melhora clínica significativa e normalização da CK.

Palavras-chave: hipotiroidismo, polimiosite, miopatias, fraqueza muscular.

\section{INTRODUÇÃO}

Os sintomas músculo-esqueléticos são freqüentes no hipotiroidismo, ocorrendo em 29\% a 78\% dos $\operatorname{casos}^{(1)}$. As alterações variam desde quadros difusos com alterações neuromusculares, fraqueza clínica em um ou mais grupos musculares, com sinais de neuropatia axonal sensitivomotora, até afecções localizadas, como a síndrome do túnel do carpo $^{(1)}$. Em geral ocorre aumento leve a moderado das enzimas musculares, particularmente da creatinaquinase $(\mathrm{CK})^{(2)}$. Nos casos de deficiência hormonal grave o nível de $\mathrm{CK}$ pode ser muito alto $(>5000 \mathrm{U} / \mathrm{L})$, no entanto as queixas musculares desaparecem ou melhoram muito após reposição hormonal adequada com levotiroxina ${ }^{(3)}$.

\begin{abstract}
Patients with hypothyroidism frequently present with musculoskeletal complaints and elevated serum levels of muscle enzymes, like creatine kinase (CK). With adequate hormonal treatment, the maintenance of high values of $C K$ and muscle symptoms are uncommon. This work reports a 47-year-old woman with hypothyroidism, proximal muscle weakness and increased CK, who didn't improved with levothyroxine treatment. The diagnosis of polymyositis was based on electromyography and muscle biopsy. After treatment with prednisone plus methotrexate and increase of the levothyroxine dose, there were a clinical improvement and a normalization of $C K$ values.
\end{abstract}

Keywords: Hypothyroidism, polymyositis, myopathies, muscle weakness.

A coexistência de hipotiroidismo e miopatia inflamatória (dermatomiosite ou polimiosite) é incomum ${ }^{(4,5,6)}$. O que geralmente tem sido observado é uma síndrome clínica semelhante à polimiosite ${ }^{(7,8)}$, com aumento de CK e envolvimento preferencial de músculos das cinturas escapular e pélvica, porém com achados eletroneuromiográficos e histológicos não compatíveis com polimiosite.

Os autores relatam o caso de uma paciente com hipotiroidismo, queixa de fraqueza muscular proximal, aumento de CK e piora progressiva dos sintomas apesar do tratamento com levotiroxina, cuja investigação levou ao diagnóstico de polimiosite. Salvo melhor juízo, este é o primeiro caso relatado em que ocorreu coexistência de hipotiroidismo, sem tiroidite autoimune, e polimiosite.

\footnotetext{
Disciplina de Reumatologia da Faculdade de Ciências Médicas da Universidade Estadual de Campinas (UNICAMP). Recebido em 03/02/03. Aprovado, após revisão, em 24/09/03.

1. Pós-graduanda da Disciplina de Reumatologia da FCM/UNICAMP.

2. Professor(a) assistente doutor(a) da Disciplina de Reumatologia da FCM/UNICAMP.

3. Professor(a) Titular da Disciplina de Reumatologia da FCM/UNICAMP.

4. Professor assistente doutor do Departamento de Anatomia-Patológica da FCM/UNICAMP.

Endereço para correspondência: Maize Fernanda Bonim Singh, Caixa Postal 6145, UNICAMP, Campinas, SP, CEP 13083-970; e-mail: masingh@unicamp.br
} 


\section{RELATO DE CASO}

Paciente do sexo feminino, parda, 47 anos, casada, do lar. A paciente foi atendida no Ambulatório de Reumatologia do HC/UNICAMP em outubro de 2000 apresentando, havia 4 meses, febre diária não aferida, fraqueza muscular em cinturas escapular e pélvica, disfagia alta para semi-sólidos, tosse não-produtiva, pele seca e edema generalizado. Após 1 mês do início desses sintomas foi feito diagnóstico de hipotiroidismo e iniciado tratamento com levotiroxina. A paciente não apresentou melhora dos sintomas e progrediu com dificuldade para caminhar e subir escadas (relatadas como fraqueza). Negava lesões cutâneas, dispnéia ou alterações da sensibilidade. Não apresentava antecedentes pessoais ou familiares relevantes. Medicamentos em uso: levotiroxina $50 \mathrm{mcg} / \mathrm{dia}$, propranolol $40 \mathrm{mg} /$ dia e, em caso de dor, diclofenaco sódico $150 \mathrm{mg} /$ dia.

Ao exame físico a paciente encontrava-se em bom estado geral, levemente descorada, hidratada, eupnéica, acianótica, anictérica, afebril, com PA $=90 \times 60 \mathrm{mmHg}$ e FC= 78 bpm. Pele com edema subcutâneo leve localizado no dorso dos pés. Avaliação cardíaca, pulmonar e abdominal sem alterações. Exame neurológico: reflexos osteotendíneos hipoativos globalmente; força muscular grau IV em membros superiores e grau $\mathrm{V}$ em membros inferiores; marcha miopática de esforço; incapacidade para realizar genuflexão; sem alterações da sensibilidade. Avaliação ginecológica normal.

A investigação complementar demonstrou: hemograma com anemia (Hb 8,92), CK: 8593 (normal: até $145 \mathrm{U} / \mathrm{L}$ ), LDH: 3415 (normal: 240-479 U/L), AST: 411 (normal: 10-35 U/L) e ALT: 312 (normal: 10-40 U/L). Fosfatase alcalina e gama-GT normais. VHS: $81 \mathrm{~mm}$. FAN: não reagente. TSH: 14,72 (normal: 0,35-4,2 $\mu \mathrm{UI} / \mathrm{ml}$ ), T4L: 1,22 (normal). A pesquisa de anticorpos anti-tiroideanos (frações microssomal e tireoglobulina) foi negativa em duas ocasiões. Sorologias para hepatite B e C, HIV e sífilis negativas. Urina I: presença de traços de proteína, hemoglobina $4+$ e cilindros hialinos e granulosos; hemácias e leucócitos normais. Radiografia de tórax, endoscopia digestiva alta e ecografia abdominal e pélvica normais.

A eletroneuromiografia mostrou as seguintes alterações: 1) condução nervosa: redução da amplitude dos potenciais obtidos com preservação da latência distal e velocidades; 2) eletromiografia: a) fibrilação: ondas positivas difusas em todos os músculos e pontos amostrados, b) potenciais de morfologia normal entremeados de potenciais polifásicos de curta duração, c) alterações morfológicas tipo miopático predominando nos músculos proximais. Conclusão: processo neuropático difuso sensitivo/motor axonal moderado e processo miopático difuso grave ativo, com predomínio em musculatura proximal, compatível com miopatia inflamatória.

Na biópsia muscular foi observado (Figuras 1 a 4): 1) HE e TRI: fragmento de músculo esquelético mostrando alterações inflamatórias intensas. Presença de várias fibras necróticas em fagocitose ou com aspecto regenerativo. Muitas fibras moderadamente atróficas, mas mantendo a arquitetura interna normal. Notou-se também infiltrado inflamatório crônico inespecífico entre as fibras, tanto no endomísio como no perimísio, mais intenso em alguns fascículos. Não foi observada atrofia perifascicular. No perimísio notaram-se alguns adipócitos. As artérias e veias observadas tinham aspecto normal. Não foi possível afastar que houvessem vasos afetados em meio ao intenso infiltrado no perimísio. 2) ATPase: em pHs 9.4 e 4.6 mostrou fibras de dois tipos em números equilibrados e distribuição aleatória. 3) NADH-TR e SDH: confirmaram os achados. 4) ORO: gotículas lipídicas em número e quantidade levemente acima do normal em parte das fibras, presumivelmente as do tipo 1. Nas outras fibras não foi possível demonstrar lípides. Conclusão: miopatia inflamatória intensa, com necrose e regeneração de fibras musculares.

Com base nas alterações clínicas de fraqueza muscular e grande aumento de CK, eletroneuromiografia e biópsia muscular compatíveis, foi feito diagnóstico de polimiosite. Iniciou-se tratamento com prednisona $1 \mathrm{mg} / \mathrm{kg} / \mathrm{dia}$, com adequação da dose de levotiroxina. Após um mês a paciente apresentava melhora da disfagia, desaparecimento do edema nos pés, normalização do TSH e da urina I, porém mantinha queixa de fraqueza muscular, anemia e alteração de CK, AST e ALT. Optou-se pela introdução de metotrexato subcutâneo, $15 \mathrm{mg} / \mathrm{semana}$, para controle da polimiosite e por seu efeito poupador de corticosteróide. Após trinta dias em uso de metotrexato a paciente apresentou normalização da CK, desaparecimento da anemia, da disfagia e da fraqueza muscular. A dose de prednisona foi então reduzida lentamente até $10 \mathrm{mg} /$ dia com manutenção do controle da miopatia. Posteriormente reduziuse também o metotrexato até a dose de $10 \mathrm{mg} / \mathrm{semana}$, sem recidiva dos sintomas ou das alterações laboratoriais até o momento. 


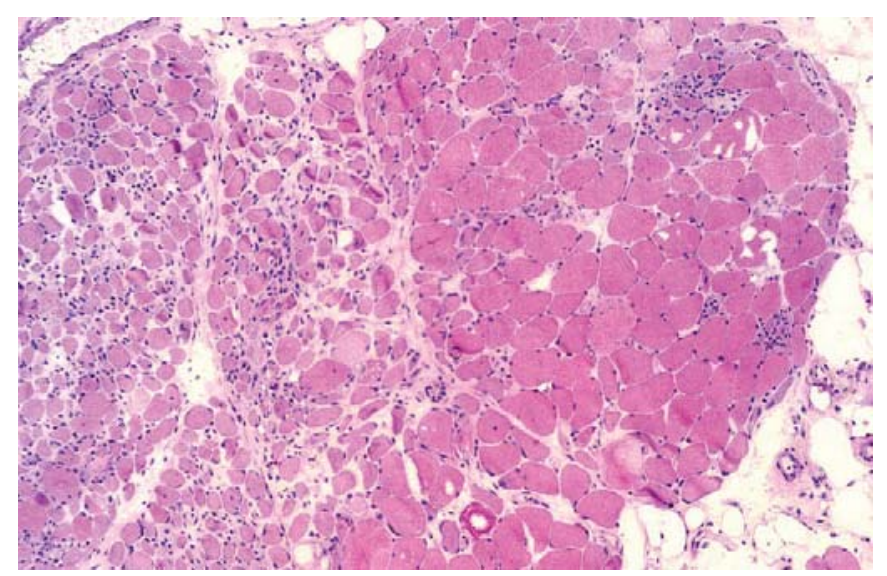

Figura 1 - Músculo esquelético (bíceps braquial), mostrando variação de diâmetro das fibras, com atrofia das fibras nos fascículos à esquerda e focos de infiltrado inflamatório.

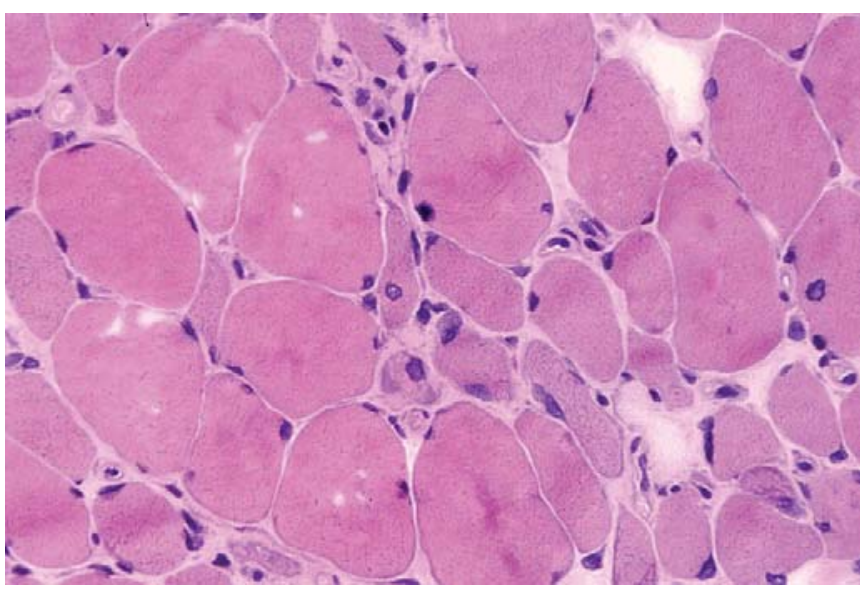

Figura 3 - Fibras com aspecto regenerativo, caracterizadas por pequeno diâmetro, tonalidade basófila e núcleos maiores, com cromatina mais frouxa.

\section{DISCUSSÃO}

Com base em levantamento realizado nos bancos de dados MEDLINE e LILACS este é o primeiro caso publicado onde houve coexistência de hipotiroidismo (sem tiroidite) e polimiosite. Gamski et al. (1988), Fujitake et al. (1994) e Taniguchi et al. (1995) relataram casos onde houve coexistência de polimiosite e hipotiroidismo, porém todos estavam associados a tiroidite crônica autoimune.

Para o diagnóstico de hipotiroidismo secundário à tiroidite autoimune (tiroidite de Hashimoto) ${ }^{(13)}$ é necessário, além do hipotiroidismo, a presença de anticorpos antitiroideanos (frações microssomal ou tireoglobulina). Mais de $80 \%$ dos pacientes com tiroidite de Hashimoto apre-

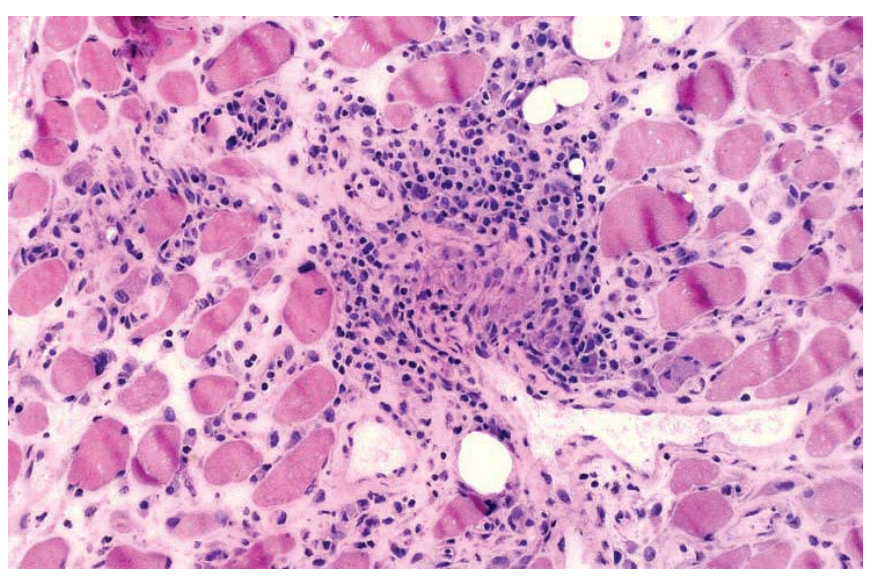

Figura 2 - Infiltrado inflamatório crônico inespecífico perivascular, avançando para o perimísio.

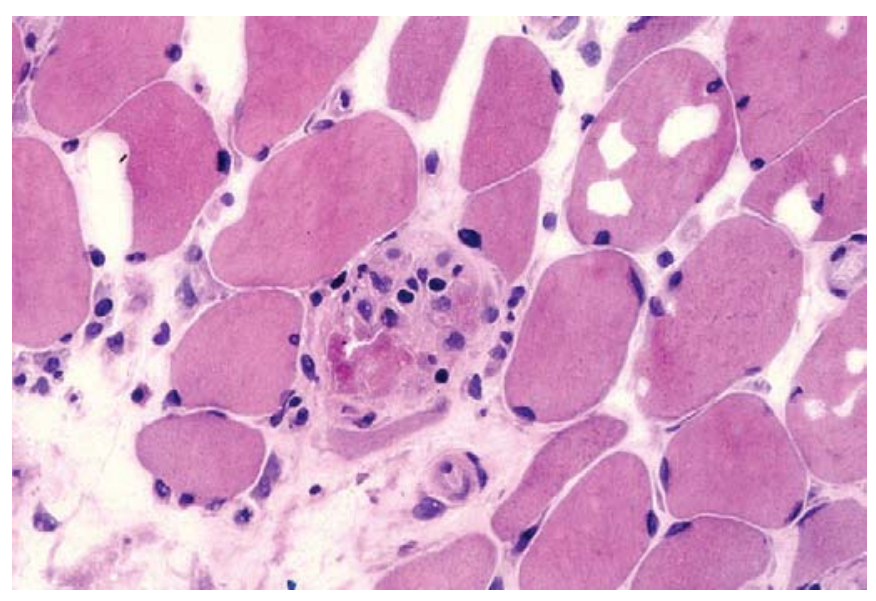

Figura 4 - No centro, fibra necrótica em processo de fagocitose; em cima e à direita, fibra com alteração vacuolar.

sentam positividade para os anticorpos anti-tiroideanos e, destes, 90\% têm o anticorpo antimicrossomal positivo. Neste relato de caso a paciente não se enquadra no diagnóstico de tiroidite autoimune pois a pesquisa de anticorpos antimicrossomal e antitireoglobulina, feita em duas ocasiões, foi negativa.

A presença de sintomas musculares nesta paciente poderia ser justificada pelo hipotiroidismo, como demonstrou Duyff et $\mathrm{al}^{(1)}$ em estudo de 45 pacientes com tiroidopatia. Nesse estudo observou-se miopatia (relatada como fraqueza) em 54\% dos pacientes e sintomas sensoriais em 29\% dos casos. Dos pacientes com hipotiroidismo 37,5\% apresentavam diminuição da força muscular, porém não inferior ao grau IV. Os níveis de CK variaram de 110 e 1542 U/L 
(aumento leve a moderado) e não se correlacionaram com a fraqueza muscular. Após um ano 33\% dos pacientes mantinham sinais e sintomas residuais. Outros estudos ${ }^{(3,9)}$ sugeriram que os níveis de CK normalizam após adequado tratamento do hipotiroidismo. Contudo, três fatores contribuíram para a hipótese de miopatia inflamatória nesta paciente: 1) ausência de resposta ao tratamento com levotiroxina, 2) presença de fraqueza muscular proximal e 3) grande aumento de CK.

$\mathrm{Na}$ investigação complementar a paciente apresentou biópsia muscular com alterações características de polimiosite: fibras necróticas entremeadas a outras de aspecto regenerativo ou normal, processo inflamatório tanto no endomísio como no perimísio e atrofia não-seletiva das fibras musculares (I e II). A eletroneuromiografia (ENM), por sua vez, evidenciou tanto alterações neuropáticas como miopáticas, porém com predomínio e maior intensidade das miopáticas, além de outras características comuns à polimiosite (fibrilação espontânea e potenciais de placa motora polifásicos de curta duração). No hipotiroidismo as alterações histopatológicas são inespecíficas, contudo as mais comuns são: presença de atrofia isolada das fibras musculares tipo II, acúmulo de glicogênio e alteração no padrão

\section{REFERÊNCIAS}

1. Duyff RF, Van den Bosch J, Laman DM, van Loon BJ, Linseen WH. Neuromuscular findings in thyroid dysfunction: a prospective clinical and electrodiagnostic study. J Neurol Neurosurg Psychiatry 2000;68:750-5.

2. Mastaglia FL, Ojeda VJ, Sarnat HB, Kakulas BA. Myopathies associated with hypothyroidism: a review based upon 13 cases. Aust N Z J Med 1988;18:799-806.

3. Finsterer J, Stollberger C, Grossenger C, Kroiss A. Hypothyroid myopathy with unusually high serum creatine kinase values. Horm Res 1999;52:205-8.

4. Fujitake J, Ishikawa Y, Ishimaru S, Koh T, Tatsuoka Y. Localized polymyositis associated with chronic thyroiditis. J Rheumatol 1994;21:1147-9.

5. Taniguchi A, Niwa A, Nakayama S, Hamaguchi Y, Kuzuhara S. Polymyositis with rimmed vacuoles in a case of chronic thyroiditis [abstract]. Rinsho Shinkeigaku 1995;35:403-7.

6. Gamsky TE, Chan MK. Coexistent dermatomyositis and autoimmune thyroiditis. West J Med 1988;148:213-4. oxidativo das células ${ }^{(10-12)}$. Na ENM predominam as alterações neuropáticas, geralmente polineuropatia sensitiva ${ }^{(1)}$.

Este caso não parece ter relação com vários relatos descrevendo uma síndrome semelhante à polimiosite, que ocorre em pacientes com hipotiroidismo ${ }^{(7,8)}$. Nesses casos houve fraqueza muscular proximal, aumento acentuado da CK e ausência de alterações eletroneuromiográficas ou histopatológicas compatíveis com miopatia inflamatória, além de normalização do quadro clínico e laboratorial após tratamento com reposição hormonal adequada. A paciente aqui relatada não apresentou a mesma evolução, ocorrendo, inclusive, piora da sintomatologia. A normalização da CK e desaparecimento dos sintomas só ocorreu após tratamento com prednisona e metotrexato, o que reforça a hipótese de que a sintomatologia da paciente devia-se, em sua maioria, à miopatia inflamatória.

O estudo deste caso conclui que as miopatias inflamatórias devem ser incluídas no diagnóstico diferencial de pacientes com hipotiroidismo onde há grandes aumentos de CK e melhora clínica insatisfatória com o tratamento hormonal. Ressalta-se, ainda, a importância da realização de ENM e biópsia muscular nesses casos, pois o quadro clínico pode ser semelhante nas duas doenças.

7. Hochberg MC, Koppes GM, Edwards CQ, Barnes HV, Arnett FC. Hypothyroidism presenting as a polymyositis-like syndrome: report of two cases. Arthritis Rheum 1976;19:1363-6.

8. Ciompi ML, Zuccotti M, Bazzichi L, Pucetti L. Polymyositis-like syndrome in hypothryroidism: report of two cases. Thyroidology 1994;6:33-6.

9. Rodolico C, Toscano A, Benvenga S, et al. Myopathy as the persistently isolated symptomatology of primary autoimmune hypothryroidism. Thryroid 1998;8:1033-8.

10. Lin RT, Liu CK, Tai CT, Lai CL. Hypothyroid myopathypathological and ultrastructural study. Kaohsiung J Med Sci 2000;16:68-75.

11. Modi G. Cores in hypothyroid myopathy: a clinical, histological and immunofluorescence study. J Neurol Sci 2000;175:28-32.

12. Monforte R, Fernandez-Sola J, Casademont J, Vernet M, Grau JM, Urbano-Marquez A. Hypothyroid myopathy. A clinical and histological prospective study of 19 patients. Med Clin (Barc) 1990;95:126-9.

13. Singer PA, Cooper DA, Levy EG, et al. Treatment guidelines for patients with hyperthyroidism and hypothyroidism. JAMA 1995;273: 808-12. 